\title{
WEBER, Hartwig, »Von des verführten Kinder Zauberei«. Hexenprozesse gegen Kinder im alten Württemberg
}

\section{Paulette Choné}

\section{(2) OpenEdition \\ Journals}

Édition électronique

URL : http://journals.openedition.org/ifha/1539

DOI : 10.4000/ifha.1539

ISSN : 2198-8943

Éditeur

IFRA - Institut franco-allemand (sciences historiques et sociales)

Référence électronique

Paulette Choné, «WEBER, Hartwig, »Von des verführten Kinder Zauberei«. Hexenprozesse gegen Kinder im alten Württemberg », Revue de l'IFHA [En ligne], Date de recension, mis en ligne le 01 janvier 1997, consulté le 22 septembre 2020. URL : http://journals.openedition.org/ifha/1539 ; DOI : https://doi.org/ 10.4000/ifha.1539

Ce document a été généré automatiquement le 22 septembre 2020.

(CIFHA 


\title{
WEBER, Hartwig, »Von des verführten Kinder Zauberei . Hexenprozesse gegen Kinder im alten Württemberg
}

\author{
Paulette Choné
}

1 L'auteur, professeur de théologie protestante et de pédagogie de la religion à la Pädagogische Hochschule de Heidelberg, avait publié en 1991 un ouvrage sur la place des enfants mineurs dans la vague de sorcellerie du XVIIe s. et sa répression (Kinderhexenprozesse, Frankfurt a. Main). Il y mettait déjà en évidence cette donnée que la plupart des spécialistes d'un domaine difficile ont aperçue sans l'étudier pour elle-même: le comportement étrange des enfants qui hors de toute contrainte dénoncent leurs proches ou s'accusent eux-mêmes de pratiques maléfiques. Le premier livre utilisait notamment des procédures à l'encontre de mineurs dans la ville de Reutligen. Celui-ci prend plus nettement le parti de conduire l'enquête dans une aire politique et géographique donnée, le duché de Wurtemberg, tout au long d'un XVIIe s. que les 37 documents exploités (17 actes transcrits en annexe) font largement déborder sur la première moitié du XVIIIe s. Le projet - ou l'hypothèse - n'est pas mince: il s'agit de décrire, à partir des procédures, l'univers mental des enfants de ce temps, "ce qu'ils ont cru, pensé et senti«. Une telle approche peut rendre perplexe, tant nous sommes habitués à considérer ces documents avec précaution, ou à les suspecter de n'être que les produits fabriqués de la culture des magistrats. Mais du point de vue d'une anthropologie historique qui s'attache à $\mathrm{y}$ identifier fragments de récits autobiographiques et situations concrètes de la vie, ils ne sauraient être totalement disqualifiés. Bien au contraire, ils apparaissent comme un matériau irremplaçable pour une "histoire du quotidien« (Alltagsgeschichte) à l'époque moderne. Ils livrent en effet, souvent sans nul apprêt, des mots, des objets, des expériences récurrentes ou singulières auxquels très peu d'autres documents donnent accès. L'ouvrage tire sa valeur du fait qu'il renvoie croyances et représentations à ce contexte concret d'un univers matériel et des destins individuels. 
2 La nouveauté du propos réside moins dans ce point de méthode, que dans la confrontation directe entre la subjectivité des jeunes prévenus, les mythes collectifs relatifs à la sorcellerie et les normes de l'éducation religieuse et sociale. On regrettera ou appréciera - que l'ouvrage, à l'instar d'un manuel, passe d'abord en revue les courants de la recherche récente et leurs systèmes d'explication, avant d'en venir au cas des enfants sorciers dans le Wurtemberg luthérien et à une interprétation surtout psychologique de leurs témoignages.

3 Quant aux illustrations convoquées pour appuyer ce travail, elles mériteraient à elles seules une étude, tant y éclate la distance - et la menace de contresens - entre les scènes représentant les séquences conventionnelles $\mathrm{du}$ commerce diabolique, et les élaborations symboliques complexes pratiquées au tout début du XVIe s. par de grands artistes tels qu'Hans Baldung Grien, Dürer et Cranach.

4 Paulette CHONÉ 